\title{
Evaluation of HIV/AIDS Patients' Knowledge on Antiretroviral Drugs
}

\author{
Regina Flávia de Castro Almeida and Anya Pimentel Gomes Fernandes Vieira \\ Master's Program in Public Health - University of Fortaleza (UNIFOR); Fortaleza, CE, Brazil
}

\begin{abstract}
Lack of information on antiretroviral drugs or the misunderstanding of available information can facilitate incorrect use of such drugs. This can result in non-adherence to the prescribed regimen, leading to a great possibility of a therapeutic failure. The aim of this study was to know which information HIV/AIDS patients, who receive their medicines at the pharmacy of a reference hospital in the northeast Brazil, have on the drugs they use, the source of this information and whether there is a need for additional information. A total of 195 HIV/AIDS patients, who were using either zidovudina + lamivudina 300+150mg (AZT+3TC), efavirenz 600mg (EFZ) or lopinavir/ritonavir 133.33/ 33mg (LPV/r), were interviewed. The mean age was 41 years $(\mathrm{SD}=9.55)$ and $70.8 \%$ were males. Of the total, $55.4 \%$ didn't know the effect of the drug in the organism; $35.9 \%$ were unaware of the necessity of taking antiretroviral drugs for the rest of their lives; only $14.4 \%$ knew how to proceed when a dosage was missed; $22.1 \%$ said they could die and the same number of individuals believed in aggravation of the disease in case of treatment interruption. The majority, $68.2 \%$, considered it very necessary to receive drug information. The results show that there is an apparent lack of general information among users of antiretroviral drugs, and at the same time a need for it. It is necessary that all professionals involved in the health care of the patients agree that an efficient supply of information on prescribed drugs is an ethical component of the treatment that favors and fosters its adherence.

Key-Words: HIV/AIDS, drug information, antiretroviral, adherence, non-adherence.
\end{abstract}

According to the National Program for STD and AIDS, since the identification of the first case of AIDS in 1980 until June 2006, around 433,000 cases of the disease have been identified in Brazil and currently it is estimated that 590,000 people live with HIV or AIDS in the country [1].

In the search for improvement in healthcare and therefore in quality of life for people living with HIV/AIDS, Brazil has adopted the policy of free and universal access to antiretroviral therapy (ART), and today approximately 170,000 people are benefited with the drugs that the Brazilian program to combat AIDS provides through the public health system. These patients are concentrated in large urban centers such as the city of Fortaleza, 5th largest city in the country and 10th in number of cases of AIDS in Brazil [1].

In Fortaleza there are 10 (ten) Drug Dispenser Units (UDM) for the care of HIV-positive patients. In June 2006, the number of patients receiving antiretroviral drugs in these units was 2,787; 2,709 adults (97\%) and 78 children (3\%). The unit that concentrates the largest number of patients is the São José Hospital of Infectious Diseases (HSJ), making it the largest reference center for this disease in the state. At the time of this study, the number of patients receiving antiretroviral drugs at HSJ was 2,272; 2,202 adults and 70 children, representing approximately $81.5 \%$ of HIV-positive patients in drug treatment in the State of Ceará [2].

Remission of the infection caused by HIV can be obtained for a long period through a combination of antiretroviral drugs, but the success of the treatment of HIV infection depends, Received on 9 March 2009; revised 15 June 2009.

Address for correspondence: Dr. Regina Flávia de Castro Almeida. Av. Monsenhor Tabosa, 1165. Fortaleza, Ceará, Brazil. Zip code: 60165011. Phone: +55-85-9984-6767. Fax: +55-85-3219-1666. E-mail: reginaflavia@gmail.com.

The Brazilian Journal of Infectious Diseases

2009;13(3):183-190. (C) 2009 by The Brazilian Journal of Infectious Diseases and Contexto Publishing. All rights reserved. fundamentally, on good adherence of the patient, without which there is great possibility of therapeutic failure. The patient needs to follow the ART correctly, taking at least 95\% of prescribed doses in the recommended schedule [3-5]. The failure of therapy leads to continuous viral replication in the presence of antiretroviral drugs, which results in successive change of combinations, reducing future treatment options $[6,7]$. However, despite the serious implications of nonadherence and the consequent good prognosis of an effective therapy, available studies on the subject show that the rate of adherence to antiretroviral drugs varies between 40 and $80 \%$ [8-10].

The lack of information about drugs in usage is pointed as one of the most significant reasons why individuals do not adequately follow their treatment [11]. However, the vast literature that deals with non-adherence to antiretroviral treatment is very limited in respect to studies that monitor the quantity and quality of information that is given to the patient about the medication he/she is prescribed, and even more limited in respect to studies that relate information to higher or lower adherence to drug treatment.

It is believed that a greater understanding of the drugs prescribed facilitates the dialogue between patients and health professionals, fosters a more active participation of the user in the care of his/her health, and thus impacts positively on adherence to treatment with consequent possibility of more success in the results. Little is known about the level of knowledge of HIV/AIDS patients in relation to the medication they use, especially in the northeast of Brazil, which may influence their adherence to treatment. The aim of this study is to describe what information HIV/AIDS patients who receive their antiretroviral drugs at the pharmacy of a reference hospital have on the drugs they are using, where this information comes from, and whether there is the need for further and more detailed information. 


\section{Material and Methods}

Type of Study

Cross-sectional study with quantitative approach and descriptive characteristics from a survey with a group of HIVpositive patients in use of antiretroviral drugs.

\section{Description of the Location of the Study}

The São José Hospital of Infectious Diseases (HSJ), located in the city of Fortaleza, capital of the state of Ceara in northeastern Brazil was chosen for being a reference in the state for tertiary level of health care with the greater number of consultations and hospitalizations due to AIDS in this state. The study was evaluated and approved by the São José Hospital Ethics Committee.

\section{Population}

The study included individuals of both sexes, HIV-positive (symptomatic and asymptomatic), residents in the state of Ceará, aged above 18 years, in use of at least one of the antiretroviral drugs of choice for initial therapy and receiving these medicines regularly as an outpatient in HSJ. Those drugs are: zidovudine + lamivudine $300+150 \mathrm{mg}(\mathrm{AZT}+3 \mathrm{TC})$, efavirenz 600mg (EFZ) and lopinavir / ritonavir 133.33/33mg (LPV/r) [13]. The monthly bulletin for evaluation and use of drugs/AIDS from the HSJ referring to the month of June 2006 indicates that 1,510 patients received AZT+3TC, 930 received EFZ and 449 received LPV/r [2].

All patients receiving medication for the first time, patients evidently unable to express themselves with clarity and lucidity, and those who did not have minimum autonomy to make decisions in respect to their treatment were excluded from the study.

\section{Size and Selection of Sample}

Assuming a tolerable sampling error of $7 \%$ in the studied population and using the formula below, a sample of 187 individuals was calculated.

$$
\begin{aligned}
& \mathrm{N}_{0}=1 / \mathrm{E}_{0}^{2} \\
& \mathrm{n}=\mathrm{N} \cdot \mathrm{n}_{0} / \mathrm{n}_{0}+\mathrm{N}
\end{aligned}
$$

$\mathrm{N}=$ population size $(2,272) ; \mathrm{E}_{0}=$ tolerable sampling error $(7 \%=0.07)$; $\mathrm{n}_{0}=$ first approximation of sample size (204); $\mathrm{n}$ = sample size (187).

\section{Data Collection}

A structured questionnaire was used to verify the knowledge of patients on the antiretroviral drugs they use, what are their more common questions, and what other information would be of interest for them.

The questionnaire was divided into three parts. The first part, with demographic data to identify the interviewee through the initials of the name, sex, age and education. The second part, with data on the drugs in usage and questions about the knowledge of information related to the drug itself, such as action, duration of treatment, prescribed dosage, proper conduct when missing doses, storage, adverse reactions, interactions with food and other drugs and consequences of treatment interruption. The third part, with about sources of information available and the importance or not of receiving information about medicines.

The selected patients received clarification on the study, and those who consented in participating were asked to sign the Term of Free and Informed Consent (TFIC).

The descriptive statistical analysis of collected data was performed using the program SPSS 15.0 for Windows (Statistical Package for the Social Sciences Inc, Chicago, IL, USA).

\section{Results}

Data analysis for the identification of 195 people interviewed showed an average age of 41 years ( $S D=9.55$ ), varying in a range between 21 and 71 years, and predominantly male (70.8\%). Regarding educational level, 106 participants (54.3\%) had not completed high school, and, of these, 60 (30.8\%) did not even finish elementary school and 10 (5.1\%) were illiterate. The average time of use of antiretroviral drugs in general was 5.3 years $(\mathrm{SD}=4.0$ ) and average time of use of the drugs under study (AZT+3TC, EFZ or LPV/r) was 3,2 years $(\mathrm{SD}=2.4$ ), while the majority $(75.3 \%)$ used AZT+3TC, with or without EFZ, LPV/r or some other antiretroviral (Table 1).

The answers to questions that directly assessed the patient's knowledge on the drug under study show that 55.4\% did not know the mode of action of the drug in fighting viruses, and $35.9 \%$ did not know that they would have to take antiretroviral drugs for life.

Only one of the interviewees could not answer the question related to the dose and frequency. It is noteworthy that in this case, considering that there may be variations in the dosages prescribed for the same medicine, there is no right or wrong answer and only the fact that the patient knew or did not know the dosage prescribed by your doctor was evaluated. As for the intake with or without food, among users of LPV/r, $69 \%$ knew that taking this drug with food is the correct way. Also, $51.7 \%$ of users of AZT +3 TC and $40.2 \%$ of users from EFZ said this to be the right behavior, but for those drugs that

Table 1. Characteristics of the patients.

\begin{tabular}{lll}
\hline & $\begin{array}{l}\text { Patients } \\
(\mathbf{n = 1 9 5 )}\end{array}$ & \\
\hline Age & $41^{*}$ & \\
Male/Female & $138 / 57$ & \\
Schooling & & \\
$\quad$ - illiterate & 10 & 5.1 \\
$\quad$ - elementary school & 27 & 13.8 \\
$\quad$ - high school & 62 & 31.8 \\
$\quad$ - college & 21 & 10.3 \\
Use of antiretrovirals (years) & $5.3^{* *}$ & \\
Use of AZT + 3TC or EFZ or LPV/r (years) & $3.2^{* * *}$ & \\
* SD = 9.5; interval: 21-71 years; ** SD = 4.0; *** SD $=2.4 ;$ SD $=$ \\
standard deviation.
\end{tabular}


Table 2. General knowledge of antiretroviral drugs.

\begin{tabular}{|c|c|c|}
\hline \multirow[b]{2}{*}{ Questions/Answers } & \multicolumn{2}{|c|}{$(\mathrm{N}=195)$} \\
\hline & n* & $\%$ \\
\hline \multicolumn{3}{|l|}{ Mechanism of action } \\
\hline Inhibits viral replication & 39 & 20 \\
\hline Other & 48 & 24.6 \\
\hline Not Known & 108 & 55.4 \\
\hline \multicolumn{3}{|l|}{ Duration of treatment } \\
\hline Lifetime & 84 & 43.1 \\
\hline Other & 41 & 21 \\
\hline Not Known & 70 & 35.9 \\
\hline \multicolumn{3}{|l|}{ Procedure when missing a dose } \\
\hline Take the missed dose no matter what time & 59 & 30.3 \\
\hline Take the missed dose if it is not near the time of the next dose & 28 & 14.4 \\
\hline Take only the next dose & 70 & 35.9 \\
\hline Other & 26 & 13.3 \\
\hline Not Known & 12 & 6.2 \\
\hline \multicolumn{3}{|l|}{ Adverse effects } \\
\hline Dizziness & 57 & 29.2 \\
\hline Nausea & 48 & 24.6 \\
\hline Nightmares & 44 & 22.6 \\
\hline Insomnia & 42 & 21.5 \\
\hline Diarrhea & 37 & 19 \\
\hline Vomiting & 35 & 17.9 \\
\hline Headaches & 15 & 7.7 \\
\hline Tiredness & 15 & 7.7 \\
\hline Lack of appetite & 12 & 6.2 \\
\hline \multicolumn{3}{|l|}{ Drug interactions } \\
\hline Not Known & 149 & 76.4 \\
\hline \multicolumn{3}{|l|}{ What happens if treatment is interrupted } \\
\hline Lower body defenses & 18 & 9.2 \\
\hline Emergence of other diseases & 36 & 18.5 \\
\hline Increase of viral load & 39 & 20 \\
\hline Worsening of disease & 43 & 22.1 \\
\hline Death & 43 & 22.1 \\
\hline Not Known & 10 & 5.1 \\
\hline Viral resistance & 6 & 3.1 \\
\hline Other occurrences & 73 & 37.6 \\
\hline
\end{tabular}

$\left.{ }^{*}\right) \mathrm{n}$ refers to the number of patients that gave the respective answer.

is not an essential conduct. Regarding the interaction with other antiretroviral drugs, 149 individuals, corresponding to $76.4 \%$, did not know if there were any drugs that should not be taken along with the antiretroviral drugs in use.

In regard to the proper conduct in case of missing a dose, only $14.4 \%$ gave a complete and correct answer saying that one should take the medicine as soon as remembered only if it was not too close to the time of the next dose, while $30.3 \%$ responded that one must take when remembered no matter what time, and $35.9 \%$ said it is correct to wait for the next dose.

As for how to store the medicines, the rate of success was high among users of the drugs studied, since $96.6 \%$ and $97.2 \%$ of users of EFZ and AZT+3TC, respectively, said they keep it at room temperature and $97.6 \%$ of those taking LPV/r keep it in the refrigerator.

Among the adverse reactions that may be present because of these drugs, the most remembered by the interviewees were: insomnia (21.5\%), nightmares (22.6\%), nausea (24.6\%) and dizziness (29.2\%).

When asked what happens if the treatment is interrupted and the patient stops taking the medicines, $22.1 \%$ responded that the person dies and the same percentage said that the disease will worsen.

Tables 2 and 3 show, in summary, the responses of the patients interviewed to the questions directly related to 
Table 3. Specific knowledge of AZT+3TC, EFZ e LPV/r (Concordance between the information on specific ARVdrugs and the responses of patients).

\begin{tabular}{|c|c|c|c|c|}
\hline Questions & ARV & $\mathbf{N}^{*}$ & $\mathbf{n}^{* *}$ & $\%$ \\
\hline \multicolumn{5}{|l|}{ Dose / Frequency } \\
\hline & AZT+3TC & 147 & & \\
\hline & 1 tablet $2 \mathrm{x} /$ day & & 143 & 97.3 \\
\hline & EFZ & 107 & & \\
\hline & 1 tablet $1 \mathrm{x} /$ day & & 104 & 97.2 \\
\hline & LPV/r & 42 & & \\
\hline & 3 tablet 2 x/day & & 38 & 90.5 \\
\hline \multirow[t]{9}{*}{ Ingestion with food } & AZT+3TC & 147 & & \\
\hline & Yes/no matter & & 88 & 59.9 \\
\hline & Not Known & & 32 & 21.8 \\
\hline & EFZ & 107 & & \\
\hline & Yes/no matter & & 53 & 49.5 \\
\hline & Not Known & & 26 & 24.3 \\
\hline & LPV/r & 42 & & \\
\hline & Yes & & 29 & 69 \\
\hline & Not Known & & 7 & 16.7 \\
\hline \multirow[t]{6}{*}{ Storage } & AZT+3TC & 147 & & \\
\hline & Room temperature & & 142 & 96.6 \\
\hline & EFZ & 107 & & \\
\hline & Room temperature & & 104 & 53.3 \\
\hline & $\mathrm{LPV} / \mathrm{r}$ & 42 & & \\
\hline & Refrigerator & & 41 & 97.6 \\
\hline
\end{tabular}

$(*) \mathrm{N}$ refers to the number of patients using the drug. $\left({ }^{* *}\right) \mathrm{n}$ refers to the number of patients that gave the respective answer.

Table 4. Information about antiretroviral drugs.

\begin{tabular}{lrr}
\hline & & $\mathbf{( N ~ = ~ 1 9 5 ) ~}$ \\
\cline { 2 - 3 } Questions/Answers & $\mathbf{n}^{*}$ & $\mathbf{\%}$ \\
\hline Receiving information & & \\
$\quad$ Received at least once & 83 & 42.6 \\
Always receive & 54 & 27.7 \\
$\quad$ Never received & 58 & 29.7 \\
Source of information & & \\
$\quad$ Doctor & 156 & 70.8 \\
Social assistant & 22 & 11.3 \\
Psychologist & 6 & 3 \\
Others & 9 & 4.61 \\
None & 30 & 15.4 \\
Necessity of receiving information & & \\
$\quad$ Necessary / very necessary & 194 & 99.5 \\
Not very necessary & 1 & 0.5 \\
Which detailed information would like to have & & 56.4 \\
Mode of action & 110 & 59 \\
Time of treatment & 115 & 45.6 \\
Drug interaction & 89 & 42.1 \\
Food interaction & 82 & 35.4 \\
Alcohol interaction & 69 & 42.6 \\
Procedure when missing a dose & 83 & 46.7 \\
Consequences of treatment interruption & 91 & 38.5 \\
How to store the medicines & 75 & 12.3 \\
Interest for information & & 3.1 \\
$\quad$ No interest - don't want to know & 24 & \\
No interest - already knows everything & 6 & \\
\hline
\end{tabular}

$(*) \mathrm{n}$ refers to the number of patients that gave the respective answer. 
antiretroviral drugs in general and those specific to the antiretroviral drugs chosen for this study.

In the third part of the questionnaire, with questions about information itself (Table 4), when asked about the importance of receiving information on medicines, $68.2 \%$ of HIV/AIDS patients considered it very necessary to receive them and only $0.5 \%$ felt little need. Of the 195 patients interviewed, $42.6 \%$ reported having already received some information on medicines, $27.7 \%$ always received information and $29.7 \%$ never received information. Seventy-two patients (36.9\%) said they never received any kind of information material.

For 110 patients $(56.4 \%)$, it was the doctor, in the beginning, who gave them all the information; 45 patients (23.1\%) obtained information through magazines; 38 (19.5\%) on television; while 78 (40\%) claim to have no other source of information than the doctor.

As it is shown in Table 3, when asked what other detailed information they wanted on the drugs they were using, the greatest curiosity of the interviewees were in relation to the duration of the treatment (59\%), followed by the mode of action of the drug in the body $(56,4 \%)$, which adverse reactions may occur (50.3\%), and what can happen if they stop the treatment (46.7\%). Of the 195 patients interviewed, 30 claimed not to have any interest in receiving more information and of those, 6 (3.1\%) said they already knew everything, while 24 (12.3\%) did not want to know anything.

\section{Discussion}

Despite substantial evidence that antiretroviral therapy is potentially effective in reducing viral load and the postponement of the onset of opportunistic diseases, recent data indicates that approximately half of patients receiving this medication fail to follow the prescription [10-12]. Studies show that providing information to patients about their disease and their treatment has long been considered a key component in the ethical and effective multidisciplinary approach needed to facilitate the adherence to any treatment, especially the most complex and long term ones, such as AIDS $[12,13]$.

The fundamental purpose of this study was to determine the level of information that people with HIV and AIDS, treated at a hospital of reference in the city Fortaleza in northeast of Brazil, has on the antiretroviral drugs they are using. This was made possible through the responses of patients to questions that were part of the structured questionnaire prepared specifically for this study and previously tested. We sought to achieve the desired number in the shortest possible time in an attempt to avoid biases related to selection of the sample and interference of the researchers.

The average age of respondents - 41 years - was a little above the average found in other studies involving patients with HIV/AIDS [8,9,14]. Most of the 195 respondents were male (70.8\%), which matches the results found in other studies $[8,9,14,15]$ and the last Epidemiological Bulletin of the Ministry of Health [16].
The epidemic of AIDS in Brazil began in the layers of the higher socioeconomic level, which was shown by the level of schooling, until between 1989 and 1996 when there was a reversal of the incidence of AIDS by level of schooling, with the rates increasing progressively in individuals of little instruction to overcome those found for individuals with more schooling. The gradual reversal was due, according to studies, to the fact that the less favored on the educational point of view, having more difficulty in receiving and assimilating the educational messages, start sexual life early, have more casual partners and makes less frequent use of condoms, making them more susceptible to sexually transmitted diseases [17]. In this study, although only 5\% of people interviewed stated they were illiterate, more than half had not completed high school and only $13.4 \%$ had attained higher education. These results, besides being in line with those found in other studies involving individuals with HIV and AIDS [9,14,18,19], show that this trend started in the 90s is still the same today. Furthermore, studies show that, although not a determining factor, the low level of education can affect adherence to treatment by influencing the understanding of the importance and understanding of the explanations given by health professionals, encouraging the misuse of the drug, especially when related to a complex treatment such as antiretroviral $[9,18,19]$.

The patients interviewed were using antiretroviral drugs, on average, for more than five years, and as for the drugs chosen as a reference for the study in question for being the most used ones, the average was around three years. Taking into account that the patient has several consultations with the doctor during the treatment and visit the pharmacy every month to receive their medicines, it was to be expected that he had a reasonable knowledge of all information considered relevant to a better understanding of their disease and the treatment. However, in the course of this work it was not what was observed.

When asked how the drug acts in the body, more than half of respondents did not know and only 20\% answered correctly saying that it inhibits viral replication, although the term most commonly used by them was "growth of the virus," showing a degree of accuracy lower than that found in a study conducted in Belo Horizonte, Brazil [14]. Knowing the correct mechanism of action of the drug with certainty will avoid patients coming to conclusions such as "it (the drug) cures" or "it (the drug) kills the worm," which are a false idea of healing, or make them believe in explanations that are very different from the truth, such as "(the drug) is moving inside the blood," " (the drug) is fighting a type of cell” or "(the drug) is a barrier of protection," which are examples of responses observed in this study.

Similarly, only $43.1 \%$ of respondents knew that they would have to take medicines for the rest of their lives, which means that more than half did not know or mistakenly knew how long they would be taking their medicines. Answers as "more or less for 20 years" or "until I am cured" give the illusion that 
there is healing, which, at least so far, does not correspond to reality. For some respondents, only God or the doctor could set this time. The clarification of those basic issues early in the treatment prevents not only the belief in the unreal but also in absurds, such as "until the appearance of sequels" or "for an unspecified period of time for being it a pre-existing condition.”

It should be noted that, although there is evidence of an association between adherence and positive and negative expectations for the patient, the belief in the efficacy of treatment has a strong positive effect [20]. Therefore, it is believed that if the information is passed on in a balanced manner, not alarmist, honestly assessing the pros and cons of treatment, it is preferable that the patient knows the true prognosis than have false beliefs [21].

Almost all the respondents (mean = 95\%) answered correctly and safely to the issues of dose and frequency, showing an index slightly higher than those found in previous studies [14,22]. This information is relevant, whereas the correct observance of these items is critical for treatment success. However, showing agreement with other previous studies $[14,23]$, the same security was not observed in respect to the recommendation on intake of the drug with or without food. Among the users of LPV/r, 69\% knew that it is advisable to take it along with food, showing more knowledge than the users of AZT+3TC and EFZ, since variation in answering “yes”, “it doesn't matter” and “no” indicates uncertainty about the correct procedure. This result is not surprising, if it is taken into account that the document of recommendations for antiretroviral therapy from the Ministry of Health [24] recommends the intake of LPV/r with food and makes no major restrictions to $\mathrm{AZT}+3 \mathrm{TC}$ and $\mathrm{EFZ}$, therefore it is assumed that health professionals also give more emphasis to the procedure with LPV/r when advising their patients.

The high percentage (76.4\%) of people interviewed who did not know if there is any drug that should not be used along with antiretrovirals is worrying, because it is known that some types of drugs, both legal or illegal (e.g. simvastatin, ergotamine, cisapride, heroin, methamphetamine, among others), may modify the effect of certain antiretroviral drugs when used concurrently, making them less effective or increasing its effects, leading to dangerous reactions in the body or the failure of the treatment against AIDS [1]. Being selfmedication a common practice in our culture, it becomes an essential role of health professionals, especially drugs prescribers and pharmacists, to guide the patients against inadequate use of medicines, including herbal, in an attempt to minimize negative interference in the treatment.

Regarding the correct procedure when missing a dose, only 28 (14.4\%) of 195 persons interviewed showed more knowledge by saying that in case of forgetting to take a dose one should only take the missed dose if it was not near the time of the next dose. The other reviews are divided mainly between taking as soon as remembered and simply waiting for the next time. One of the respondents referred to the fact that the doctor said "it is important to take, no matter what time." More worrying were the comments of some who said that when they forget to take one dose, they double the next dose, increasing the likelihood of the emergence of side effects without positively affecting the therapeutic outcome. It was also mentioned by some interviewees that their doctors told them not to worry much if they "occasionally" missed a dose. The question is how to define "occasionally" as the term has a subjective, personal connotation, and therefore variable. Some patients reported the habit of stopping the medicine intake during the weekend or on holidays so they could drink alcohol, to "cleanse the blood," or even to "take a break from medicine,” a practice already mentioned in other studies involving patients of HIV/AIDS [25].

The main cause of virus resistance to antiretrovirals is the interruption in treatment and although there are no studies determining the level of non-compliance that is associated with an increased risk of resistance, it has been suggested that the minimal failure is sufficient to lead to therapeutic failure $[26,27]$, preventing the product to make the necessary effect, impairing the treatment and, consequently, the clinical improvement.

The question on the form of storage of medicines had a degree of accuracy of the responses quite high. Of the 42 patients using LPV/r, 97.6\% correctly stated they kept the drug in the refrigerator and only 1 (one) patient did not follow this guideline. Among the users of AZT+3TC and EFZ, the vast majority (96.6\%) said they store the drug at room temperature, although it has been observed by interviewers that for many users it was considered room temperature to be any place that was not the refrigerator (eg closets, drawers, bags inside the drawer of the wardrobe, bathroom cabinets etc.). Considering the guidelines of the manufacturers of $\mathrm{AZT}+3 \mathrm{TC}$ and EFZ, room temperature is temperature below $30^{\circ} \mathrm{C}$. So, it is disturbing the assumption that many patients are storing their medicines in places more humid or under higher temperatures than recommended, either to ensure secrecy, or for lack of more precise guidance.

In this study, the patients are asked what adverse reactions the drugs they were using could cause and, in general, little knowledge was shown about the subject. Dizziness (29.2\%), nausea $(24.6 \%)$ and nightmares $(21.6 \%)$ were the most mentioned, followed by insomnia (21.5\%), diarrhea (19\%) and vomiting (17.9\%). A variety of adverse reactions mentioned, and not all of them related to drugs, shows a tendency of respondents to relate to the drug any symptoms they may have experienced, a fact already observed in previous studies [25].

It is known that there are many side effects affecting the different systems of the body that can be observed as a consequence of treatment with antiretroviral drugs, some of them quite severe, and in some cases, fatal. The more complex the treatment, i.e. the greater the number of drugs combined in the scheme to combat HIV, either antiretrovirals drugs or not, the greater the toxicity and occurrence of side effects $[19,28]$. 
Existing studies on adherence to ART are unanimous in saying that adverse reactions are significantly associated with poor adherence, with many considering that the most important cause related to the treatment $[15,27,29,30,31]$. There are researches that identify gastrointestinal problems, mainly nausea and diarrhea, as the major cause (44\%) of discontinuation of ART [32].

Therefore, it is essential that health professionals dealing with patients with HIV/AIDS are aware of the adverse reactions that may arise with antiretroviral drugs, adversely affecting the quality of their lives, and therefore influencing nonadherence to treatment [28]. Knowing this, health professionals can inform and advise the patient about these reactions, with caution to avoid that, by self-suggestion, the information becomes prophecies, as well as creates appropriate and effective strategies to control them.

Regarding the question about what may occur if the person stops taking the medication, while the same number of patients believe that death (22\%) or worsening of disease (22\%) is what happens, the possibility that the virus becomes resistant to drugs was mentioned by only 6 (3.1\%) patients, which is a cause of concern as it shows poor knowledge of HIV /AIDS patients on viral resistance, and as a consequence, on the importance of this issue on the adherence to treatment. Even more significant is the quality of the information some interviewees have, indicating that, somehow, they had access to information, but it was not well understood, making them believe, for example, that if one stops the treatment "the CD4 count will decrease, viral load will decrease and it will lower the defenses " or "the body humanity (immunity) weakens" or "the microbes multiply and I will have to take (the drug) again”. It is believed that information alone, when passed correctly and constantly, is able to promote adherence to treatment [33], and, for that reason, health care professionals in direct contact with patients, need to, besides providing information, make sure that the information was understood and accepted, and this can be done during the conversation over the consultations.

This study found that the large percentage (99.5\%) of patients who consider it necessary or even very necessary, to receive information on antiretroviral drugs shows the interest of patients for their treatment. It was observed that, among the 195 people interviewed, 110 (70.8\%) received information from the doctor at the beginning of treatment, although 28 of these people (14.4\%) have said that the doctor only advised about dosage and frequency. These results differ from another previous study, where a greater proportion of patients received guidance through the pharmacist [14]. Among other possible sources of information, magazines (23.1\%) and television (19.5\%) were the most mentioned, which is in agreement with other studies [25]. However, although the electronic media (internet, television) and groups and associations are gaining space as influential informers, health professionals still seem to be the largest, most secure and reliable source of information on medicines to patients.
Showing results consistent with others found in the literature [34], this study showed that the interest of patients is greater in the following aspects of medical treatment: length of time of treatment, mode of action, adverse reactions and discontinuation of the drugs. However, you may notice that the interest or the need for information on the drug is highly variable among its users, as well as variable is the preference for certain subjects. This study also shows that 24 (12.3\%) among 195 patients interviewed did not want to receive any information and, in this case, provided that they do not come to be harmed by that choice, their wishes must be met [35]. The health care professional involved in the care of these people should exploit these preferences and provide the information or not, always considering that the quantity and complexity of such information should be tailored to the needs and capacity of understanding of each patient.

\section{Conclusions and Final Considerations}

The lack of knowledge about antiretroviral drugs among patients with HIV/AIDS is evident according to this study. The analysis of responses from users of antiretroviral drugs interviewed for this study shows that, despite being sure about the number of pills and frequency with which they must take them, they lack more knowledge about other aspects of drug therapy. It appears that such basic information was provided, according to most, only by the doctor at the time of prescription, when it is known that giving patients adequate information about the medicines that are prescribed, on the behavior to be adopted between the diagnosis and treatment, and on the conduct that provide a better quality of life is a task not only of doctors and pharmacists, but also for all health professionals involved in the care of the patient.

Those who believe in the necessity and benefit of the medication are more likely to follow the treatment properly, so the quantity and quality of information have the potential to influence the ability of individuals to judge and participate in decisions concerning their treatment. The doctor, being the one who decides which product the patient will use, is the one who initiate the transmission of necessary information. The pharmacist at the time of dispensing, should continue the flow of information initiated by the physician during the consultation, ensuring that the guidance given was well understood by the patient. It is their responsibility to work together, along with the entire team of health professionals, to overcome failures of communication and obstacles, especially those imposed by shortages of public services, most notably the lack of time, so that the patient, feeling secure and confident, will more cordially accept what is informed and proposed, keeping better expectations regarding treatment.

\section{References}

1. Brasil. Ministério da Saúde. PN-DST/AIDS - Programa Nacional de DST e Aids. Brasília: Coordenação Nacional de DST e AIDS. 2006. Disponível em: http://www.aids.gov.br

2. Ceará. Secretaria da Saúde. Núcleo de Assistência Farmacêutica. Boletim mensal para avaliação do uso de medicamentos/AIDS. Junho 2006. 
3. Shannon K., Kerr T., Lai C., Ishida T. et al. Nonadherence to Antiretroviral Therapy Among a Community With Endemic Rates of Injection Drug Use. J Int Assoc Physicians Aids Care 2005;4(3).

4. Zorrilla C.D., Santiago L.E., Knubson D. et al. Greater adherence to highly active antiretroviral therapy (HAART) between pregnant versus non-pregnant women living with HIV. Cell Mol Biol 2003;49 (8): 1187-92.

5. Castro, A. Adherence to antiretroviral therapy: Merging the clinical and social course of AIDS. PLoS Med. 2005;2(12): e338.

6. Gottlieb S. Non-compliance often the cause when AIDS drugs “fail”. BMJ. 2000; 320(7229): 208.

7. Bangsberg D.R., Moss A.R., Deeks S.G. Paradoxes of adherence and drug resistance to HIV antiretroviral therapy. J Antimicrob Chemother 2004;53, 696-9.

8. Silveira V.L., Drachler M.L., Leite J.C.C., Pinheiro C.A.T. Characteristics of HIV Antiretroviral Regimen and Treatment Adherence. Braz J Infect Dis 2003;7(3):194-201.

9. Monreal M.T.F.D., Cunha R.V., Trinca L.A. Compliance to antiretroviral medication as reported by AIDS patients assisted at the University Hospital of the Federal University of Mato Grosso do Sul. Braz J Infect Dis 2002;6(1):8-14.

10. Howard A.A., Arnsten J.H., Lo Y. et al. A prospective study of adherence and viral load in a large multi-center cohort of HIVinfected women. AIDS 2002;16(16):2175-82

11. Marin, N. et al.(Org.). Assistência farmacêutica para gerentes municipais. Rio de Janeiro: OPAS/OMS, 2003.

12. Christensen A.J. Patient adherence to medical treatment regimens - Bridging the gap between behavioral science and biomedicine. U.S.A.: Yale University, 2004.

13. Garcia R., Schooley R., Badaro R. An adherence trilogy is essential for long-term HAART success. Braz J Infect Dis 2003;7(5):30714.

14. Ceccato M.G.B., Acurcio F.A., Bonolo P.F. et al. HIV patients' understanding of information on antiretroviral therapy. Cad. Saúde Pública. 2004;20(5): 1388-97.

15. Figueiredo R.M., Sinkoc V.M., Tomazim C.C. et al. Colombrini MRC. Adesão de pacientes com AIDS ao tratamento com antiretrovirais: dificuldades relatadas e proposição de medidas atenuantes em um hospital escola. Rev Latino-am Enfermagem 2001;9(4):50-5.

16. Brasil. Ministério da Saúde. Secretaria de Vigilância em Saúde Programa Nacional de DST e Aids. Boletim Epidemiológico Aids e DST. Ano III - n $1-01^{\mathrm{a}}-26^{\mathrm{a}}$ de 2006.

17. Fonseca M.G.P., Szwarcwald C.L., Bastos F.I.Análise sociodemográfica da epidemia de Aids no Brasil, 1989-1997. Rev Saúde Pública 2002;36(6):678-85

18. Lignani Junior L., Greco D., Carneiro M. Assessment of the compliance to antiretroviral drugs among HIV/AIDS patients. Rev. Saúde Pública, 2001;35(6):495-501.

19. Barroso, L.L.M.M.B. Adesão ao tratamento com antiretrovirais entre pacientes com aids em Fortaleza-CE. Online braz j nurs 2006;5(2).
20. Pinheiro C.A.T., Leite J.C.C., Drachler M.L., Silveira V.L.. Factors associated with adherence to antiretroviral therapy in HIV/ AIDS patients: a cross-sectional study in Southern Brazil. Braz J Med Biol Res. 2002;35(10): 1173-81.

21. Coulter A., Entwistle V., Gilbert D. Sharing decisions with patients: is the information good enough? BMJ 1999;318;318-22.

22. Silva T., Schenkel E.P., Mengue S.S. Nível de informação a respeito de medicamentos prescritos a pacientes ambulatoriais de hospital universitário. Cad. Saúde Pública. 2000;16(2):449-55.

23. Stone V.E., Hogan J.W., Schuman P. et al. Antiretroviral regimen complexity, self-reported adherence, and HIV patients' understanding of their regimens: survey of women in the her study. J Acquir Immune Defic Syndr. 2001;28(2):124-31.

24. Brasil. Ministério da Saúde. Consenso: Recomendações para terapia antiretroviral em adultos e adolescentes infectados pelo HIV 2005/2006. Brasília, 2005.

25. Laws M.B., Wilson I.B., Bowser D.M., Kerr S.E. Taking Antiretroviral Therapy for HIV Infection. Learning from Patients' Stories. J Gen Intern Med. 2000; 15(12): 848-58.

26. Sethi A.K., Celentano D.D., Gange S.J. et al. Association between adherence to antiretroviral therapy and human immunodeficiency virus drug resistance. Clin Infect Dis. 2003;37(8):1112-18.

27. Bangsberg D.R., Charlebois E.D., Grant R.M. et al. High levels of adherence do not prevent accumulation. AIDS 2003; 17(13):1925-32.

28. Rudorf D., Krikorian S.. Adverse Effects Associated with Antiretroviral Therapy and Potential Management Strategies. Journal of Pharmacy Practice 2005;18(4):258-77.

29. Gir E., Vaichulonis C.G., Oliveira M.D. Adesão à terapêutica antiretroviral por indivíduos com hiv/aids assistidos em uma instituição do interior paulista. Rev Latino-am Enfermagem 2005; 13(5):634-41.

30. Carvalho C.V., Duarte D.B., Merchán-Hamann E. et al. Predictors of compliance with highly active antiretroviral therapy in Brasilia, Distrito Federal, Brazil, 1999-2000. Cad. Saúde Pública. 2003;19(2): 593-604.

33. Turner B.J. Adherence to Antiretroviral Therapy by Human Immunodeficiency Virus-Infected Patients. JID 2002;185(2):S143-S151.

32. O’Brien M.E., Clark R.A., Besch C.L. et al. Patterns and Correlates of Discontinuation of the Initial HAART Regimen in an Urban Outpatient Cohort. J Acquir Immune Defic Syndr 2003;34:40714.

33. Garcia R., Ponde M., Lima M. et al. Lack of effect of motivation on the adherence of HIV-positive/AIDS patients to antiretroviral treatment. Braz J Infect Dis 2005; 9(6):494-9.

34. Dickinson D., Raynor D.K.T., Kennedy J.G.K. et al. What information do patients need about medicines? BMJ 2003;327: 861-64.

35. Kennedy J.G. "Doc, tell me what I need to know"-a doctor's perspective. BMJ 2003;327;862-63. 